\title{
NATIONAL FABRIC: UNDERSTANDING NATIONS THROUGH CONCEPTUAL METAPHOR
}

\begin{abstract}
Drawing on conceptual metaphor theory, this paper explores how NATIONS as a social entity are understood in terms of the conceptual domain of FABRIC. An analysis of concordances from the Corpus of Contemporary American English (COCA) reveals how the NATIONS as FABRIC metaphor highlights elements, concepts and practices that constitute and define nations and issues that have an impact on their identity. It also shows how this metaphor is employed for the construction of in-group and out-group identities and considers its potential role in shaping the perceptions of nations and their members. The analysis identifies metaphorical mappings between the two domains that have previously not been considered, adding to the existing research on the metaphorical representation of nations.
\end{abstract}

Key words: conceptual metaphor, metaphor theory, FABRIC, NATION

\section{Introduction}

Lakoff and Johnson's (1980) theory of conceptual metaphor redefined our understanding of the role of metaphor in language and, more importantly, thought and action. The cognitive approach to metaphor posits that our conceptual systems are underpinned by numerous conceptual metaphors, which are defined as understanding one conceptual domain - the target domain - in terms of another conceptual domain - the source domain. As a rule, target domains are areas of our experience such as emotions, life and relationships that are abstract, subjective, complex and insufficiently structured, while source domains are more concrete, well-defined and simpler phenomena; source domains are also commonly rooted in physical experience such as bodily functions and actions (see e.g. Kövecses 2010; Lakoff and Johnson 1980; Semino 2008). A target domain is understood in terms of a source domain by means of a series of systematic correspondences or cross-domain mappings (see e.g. Kövecses 2010: 77-88). This way, for example, when we say 'The idea was difficult to digest at

\footnotetext{
*Faculty of Security Studies, University of Belgrade, Gospodara Vučića 50, 11000 Belgrade, Serbia; e-mail: jbosnjak@fb.bg.ac.rs
} 
first', we understand IDEAS as FOOD. Conceptual metaphors are usually formulated as A IS B propositions, for example ARGUMENT IS WAR or TIME IS MONEY. They most readily manifest themselves in language as metaphorical linguistic expressions, but, as some scholars have demonstrated, they can have non-linguistic realizations as well (see e.g. Kövecses 2010: 63-73; Rasulić 2004: 338-433). In the first edition of Metaphors We Live By (1980), Lakoff and Johnson distinguish between structural metaphors (which help us understand one domain based on the structure of another domain e.g. IDEAS ARE FOOD), orientational metaphors (which help us conceptualize abstract domains in space, e.g. VIRTUE IS UP) and ontological metaphors (which enable us to think of abstract concepts as ENTITIES (OBJECTS and BEINGS) and MATTER/SUBSTANCE). In the second edition, however, Lakoff and Johnson (2003) abandon this classification as artificial, acknowledging that all metaphors are structural and ontological and that many are orientational; at the same time, they emphasize the importance of the classification into primary and complex metaphors, which was first described by Grady (1997a, 1997b). Grady (1997a, 1997b) makes a distinction between primary metaphors, which have independent experiential motivations and occur in language independently of other metaphors (e.g. PERSISTING IS REMAINING ERECT), and compound or complex metaphors, which are a combination of two or more primary metaphors (e.g. THEORIES ARE BUILDINGS).

Since the inception of metaphor theory, metaphor research has flourished both in terms of theory building and empirical linguistic research (see e.g. Gibbs 2006, 2008; Steen 2011) and cognitive approaches to metaphor have found their applications in numerous areas from psycholinguistics (see e.g. Gibbs and Matlock 2008) to discourse analysis and critical discourse analysis (see e.g. Charteris-Black 2004; Musolff 2012; Semino 2008).

A source domain that has been identified by metaphor scholars but not explored in depth is the conceptual domain FABRIC, whose elements relate to textiles or cloths, their production and destruction, qualities, the damage they can sustain and so forth. This paper explores the mappings of the source domain FABRIC onto NATIONS as a social entity in contemporary English. Conceptual metaphors relating to sOCIETY (see Lakoff and Johnson 1980; Kövecses 2009; Rasulić 2003, 2004; Klikovac 2008) and NATIONS (see Lakoff 1996, 2003, 2004; Musolff 2006; Santa Ana 2002) have been identified and explored separately. However, the cross-domain mappings between FABRIC and SOCIAL ENTITIES were first described in some depth by Grady (1997a, 1997b), who argues that the metaphor SOCIETY IS A FABRIC is a compound metaphor, which derives from two more basic metaphors - ORGANIZATION (ABSTRACT STRUCTURE) IS PHYSICAL STRUCTURE (also discussed by Lakoff and Johnson 1999) and MULTIPLE INTERDEPENDENCE IS INTERWEAVING. In exploring the mappings between NATIONS and FABRICS, this paper seeks to answer 
a) what mappings occur between these two domains, b) what the use of FABRIC as a source domain reveals about nations and how they are perceived and conceptualized, c) what linguistic expressions from these domains are used metaphorically, and d) if there are any differences in the use of the metaphor NATION IS A FABRIC and other related metaphors in different genres in the English language.

\section{Corpus and methodology}

The portion of the research relating to NATIONS presented in this paper is part of a more comprehensive study into the conceptual metaphors that include the source domain FABRIC and its metaphorical mappings. This research was conducted by identifying and analyzing the metaphorical uses of the noun fabric in the Corpus of Contemporary American English (COCA).

The COCA corpus was chosen because it is a well-balanced monitoring corpus of American English currently containing more than 560 million words in 220,225 texts, which are evenly divided between different genres and years (1990-2017); the texts added each year in almost equal proportion belong to five genres: spoken language, fiction, popular magazines, newspapers and academic journals (Davies 2010). The corpus was therefore deemed appropriate to provide insight into the uses of fabric in the English language although the choice of a corpus of American English necessarily meant that many of the topics and ideas occurring in the corpus were likely to relate to the U.S.

The corpus was first used to obtain all of the occurrences of the noun fabric in the corpus. A total of 11,427 concordances were found and examined further to identify any metaphorical uses. These metaphorical uses were identified using the metaphor identification procedure (MIP) formulated by the Pragglejaz Group (2007) and its expanded version MIPVU (Steen et al. 2010). Each instance was considered in an expanded context of about 100 words, but an even wider context was drawn upon when necessary. The contextual meaning of each instance of fabric was compared with the meanings provided by the Oxford Dictionaries' English Dictionary (now Lexico) and the Macmillan Dictionary, which provide both British English and North American English definitions and uses. Despite being the most comprehensive dictionary of North American English, the Merriam-Webster Unabridged dictionary was not used as the main reference because it does not make a clear distinction between basic and more abstract meanings (and therefore domains).

The basic, non-metaphorical meanings found in the corpus corresponded to the following definitions from the English Dictionary: a) Cloth produced by weaving or knitting textile fibres ('silk fabrics', 'natural fabrics', 'tightly woven fabrics'), b) The walls, floor, and roof of a building ('decay and neglect are slowly eating away at the 
building's fabric') and c) The body of a car or aircraft ('we heard creaking and rushing noises in the car's fabric'). The only abstract meaning provided by the dictionary was d) The basic structure of a society, culture, activity, etc. ('the multicultural fabric of Canadian society'). Following the MIPVU procedure, the contextual meanings identified in the corpus that were distinct from the three concrete meanings provided in a), b) and c) above, yet displayed a sufficient degree of similarity with one of them were marked as metaphorical. The analysis did not include identifying direct, indirect and implicit metaphors (see Steen et al. 2010).

Over 2,300 examples of the metaphorical use of fabric were identified in this way. These examples were then analyzed to separate all metaphorical uses where the contextual meaning contrasted with but also bore similarity to the more basic meaning in a) above - 'Cloth produced by weaving or knitting textile fibres'. This basic meaning of fabric accounted for the vast majority of the metaphorical uses of fabric identified in the corpus. SOCIAL ENTITIES, such as societies, nations, communities, families, etc., were the most frequent target domain in the corpus. Other common target domains included: THE UNIVERSE, SPACETIME, THE ENVIRONMENT, THE NATURAL WORLD, HUMAN BEINGS, THE HUMAN MIND, THE HUMAN BODY, MEMORY, MUSIC, LITERATURE, WORKS OF ART, TELEVISION, IDEAS, THE INTERNET and so forth.

The analysis presented here included all the concordances from all the genres in the COCA corpus where metaphorical mappings were discovered between the source domain FABRIC as defined in a) above and the target domain NATION defined as 'A large body of people united by common descent, history, culture, or language, inhabiting a particular country or territory' (the Oxford Dictionaries' English Dictionary/Lexico). Nations defined in this way were referred to in the corpus in a variety of ways, for example as our nation, the society and our country. Wherever it was determined from the surrounding context that the body of people referred to in a concordance corresponded to the definition of the nation provided above, these examples were included in the analysis. Other conceptual metaphors, metaphorical linguistic expressions and cross-domain mappings were not taken into consideration and will not be discussed in this paper.

A total of 487 concordances from texts dating from 1990 to 2017 were extracted from the corpus using these criteria. Although the noun fabric was used as a query to obtain the relevant concordances from the COCA corpus, all the metaphorical expressions from the domain FABRIC in the expanded context obtained for each search result were included in the analysis (see example 1). In this way, the analysis also served to identify the linguistic expressions from this domain used metaphorically.

(1) The delicate fabric that is the Lebanon polity, only recently rewoven after decades of civil war, is once again on the verge of unraveling. 


\section{Analysis and findings}

\subsection{NATIONS as FABRICS}

NATIONS were the most common social entity that FABRIC mapped onto in the corpus and metaphorical mappings between the two domains were identified in all genres. The number of concordances for all genres except fiction ranged from 96 concordances (magazines) to 133 concordances (spoken language). Texts belonging to the genre fiction in the corpus accounted for only 12 instances of cross-domain mappings between NATION and FABRIC.

Grady (1997a, 1997b) argues that the metaphor SOCIETY IS A FABRIC is a compound metaphor, which derives from two more basic, primary metaphors. The first is ORGANIZATION (ABSTRACT STRUCTURE) IS PHYSICAL STRUCTURE, which holds between various abstract concepts such as THEORIES and SOCIETIES on the one hand and physical structures such as FABRICS and BUILDINGS on the other. Grady (1997b: 274) identifies the following mappings between these two domains:
ABSTRACT ORGANIZATION
$\rightarrow \quad$ PHYSICAL STRUCTURE
Complex abstract entity
$\rightarrow \quad$ Complex physical object
Abstract constituents of the entity
$\rightarrow \quad$ Physical parts
Logical (etc.) relations among constituents
$\rightarrow \quad$ Physical arrangement of parts

The second basic metaphor is MULTIPLE INTERDEPENDENCE IS INTERWEAVING. Fabric is a prototypical example of a physical object made up of many interconnected and interdependent parts; as a complex physical entity, it helps us comprehend interconnected abstract entities (Grady 1997b: 284-285).

These mappings were all identified in the corpus. The metaphor NATIONS ARE FABRICS occurs throughout the corpus, highlighting the complexity and heterogeneity of nations and their constituent parts. These include people (example 2) as well as abstract elements (example 3).

(2) Dozens of ethnic minority groups together with the white population provide the fabric of our society.

(3) [...] a rich array of significant themes, ideas, events, individual personalities, and group identities that have created the fabric of America as a nation.

Due to its highly complex and heterogeneous nature, every nation is a unique amalgam of numerous entities, which might account for examples from the corpus in which A NATION'S FABRIC is considered to be its (UNIQUE) IDENTITY. Thus, in example 4, an embedded journalist who spent months on the presidential campaign trail in the 
U.S. believes he has become familiar with the true nature of the country. In example 5, the national fabric constitutes and defines the nation in question.

(4) I think it's - you are on the front lines of history in the most - in the most beautiful way. I mean you see it. You eat it. You live it. You breathe it. I mean, I - I never thought that I would have such an understanding of like the fabric of America.

(5) $[\ldots]$ their stories and the stories of their families and communities are $[\ldots]$ a significant and vital component of the fabric that makes America and Americans.

Another metaphorical use of fabric is to designate a nation's BASIC STRUCTURE (the only abstract, metaphorical meaning identified by dictionaries, as discussed in section 1 above). This fundamental structure refers to the abstract arrangement of the given nation's constituent parts and the relations between them (Grady's "multiple interdependence" (1997b: 284-285)). Changes to a nation's fabric, e.g. when this fabric has been or is being re-stitched and rewoven, are therefore changes to the identity of the nation (example 6) and to the relations among its members (example 7). This argument is supported by many examples where fabric is preceded by very, an intensifier (Breban and Davidse 2016; Quirk et al. 1985) "used for emphasizing how important or serious something is" (MacMillan Dictionary). The nation's fabric therefore holds the nation together and its transformation or destruction would likely mean the complete transformation of the nation in question (example 8). This metaphorical use is, consequently, very common in describing threats to a nation, as discussed in section 3.3.

(6) However, the events of the last few days have re-stitched the very fabric of Libyan society.

(7) America's social fabric is being unraveled and rewoven as we become more accepting of the differences that make each individual unique and our country so great.

(8) This is absurd, and I'm surprised that the American people will still buy into this as if they believe that the Democratic Party is here to destroy the very fabric of our country.

\subsection{Relations among the members of a nation}

As discussed above, one of the cross-domain mappings between ABSTRACT ENTITIES (such as SOCIETIES) and COMPLEX PHYSICAL OBJECTS (such as FABRICS) identified by Grady (1997a, 1997b) was the mapping of the physical arrangement of parts onto the logical 
and other relations among the constituent parts of the abstract entity. Throughout the corpus, the fabric of a nation is determined and affected by the networks of relations among its members.

Certain types of relations among the members of a nation are seen as forces that sustain nations and improve them. In general, the more relations are established among the members of a nation, the stronger the national fabric will be i.e. TO FOSTER RELATIONS AMONG THE MEMBERS OF A NATION IS TO MAINTAIN/STRENGTHEN THE NATIONAL FABRIC.

(9) Institutions, networks and groups of people, even technologies fostering relations among the members of a nation are considered to maintain and strengthen the national fabric.

Apart from the increase in the number of relations, certain types of relations among the members of a nation feature prominently in the corpus as forces that preserve and reinforce the national fabric. These are: friendship, community, solidarity, unity, tolerance, virtue, good citizenship, socially responsible behavior and similar types of values, beliefs and behavior. In some cases (example 11), these relations are considered to be the fabric of the nation. These relations are also sometimes contrasted with opposing forces, detrimental to the national fabric (example 12).

(10) Encouraging favorable behavior for the greater good helps keep the fabric of our society together.

(11) $[\ldots]$ we extend the spirit of hospitality and strengthen the fabric of friendship and community - the fabric of our nation.

(12) $[\ldots]$ it's not the health of the individual we should care about. It's the national fabric, the national community. We are one national community. We're a polarized country, we're a segmented country, but at the end of the day, we do have to preserve the idea that we have some solidarity.

\subsection{Threats to nations}

In addition to the forces that maintain or strengthen the national fabric, NATIONS are frequently conceptualized as FABRIC in order to understand and describe the forces that threaten to damage or destroy them. When this metaphor is employed to refer to the threats a nation is facing, the dominant metaphorical expressions are those referring to severe damage to a fabric or its destruction - tearing (apart/at/asunder), ripping (apart/through), rending, shredding, slashing at, fraying, unraveling and pulling apart. Verbs referring to damage not related to textiles, e.g. disrupt, and nouns that mean damage such as a rupture and a tear were one-off cases in the corpus, as were verbs expressing damage on a smaller scale (e.g. itch at). 
Just as friendship, community and unity are vital to a healthy national fabric, relations involving distrust or discord and the deterioration of social relations in general are seen as conducive to a deficient national fabric or as a direct threat to it. This includes the deterioration of relations because of internal political issues such as internal conflicts, separatism, social tensions, racial divisions, ethnic frictions and other divisive issues.

(13) "You can't trust your mother, brother, sister," he said about his homeland. "You can imagine what kind of social fabric is formed out of such a system."

(14) Where other countries were bogged down by sectarianism and civil war, Egyptians were really bonded and united together by the spirit of togetherness. And - and now we're seeing that threatened, the very social fabric of this country is being torn apart.

Some of the most frequent threats to the national fabric encountered in the corpus stem from threats such as wars, terrorism, violence, conflicts, oppression, totalitarianism, etc. However, crimes (especially illegal drug trafficking), corruption, environmental issues, natural disasters, poverty and the wealth gap, unemployment, inequality, the perceived crumbling of the educational system, and even technology all feature in the corpus as threats with the potential to inflict serious or even irreparable damage to nations.

(15) The mass killings and expulsion of tens of thousands of civilians from their homes as well as the destruction of many places of worship tore apart the very fabric of Bosnian society.

(16) Under the 40-year Marxist dictatorship of Enver Hoxha, totalitarianism destroyed the fabric of Albanian society and tradition [...]

(17) Americans were complacent as their schools crumbled, threatening the very fabric of society.

(18) The fruits of America's recent prosperity have gone disproportionately to the wealthiest in society - a trend that could eventually fray the social fabric.

Although such examples were not frequent in the corpus, individuals and groups may also pose threats to entire nations. These are almost invariably political figures and groups, presumably because only they are perceived as having influence on a national scale. These examples often contain verbs shred or slash at, indicating that the damage being inflicted is intentional.

(19) $[\ldots]$ the Liberals successfully painted the Toronto-born Harper as a farright ideologue out to shred Canada's social fabric.

(20) She [=Congresswoman Wilson] is slashing at the fabric of society, mocking the most treasured sacrifice known to free people. 
Finally, the fabric affected by any of these threats can be frayed, in tatters, torn, fragile and delicate and it can have flaws or be warped. Alternatively, it can also be repaired or restored, when relations among its members are repaired or restored, but such examples were rare in the corpus.

(21) Catastrophe still haunts the region, but of a different sort. One that threatens to tear apart the fragile fabric of a nation.

(22) $[\ldots]$ the crucial task of reconciliation and repairing a social fabric badly frayed by more than four decades of conflict.

\subsection{Parts of the national fabric}

NATIONS are also conceptualized as FABRICs to refer to the constituents of nations, such as individuals, values, customs, practices, elements of culture and works of art, especially when these are seen as fundamental and inseparable parts of their respective nations. The corresponding metaphor would be TO BE A(N) (INSEPARABLE/ VITAL/UbiQuitous) PART OF A NATION IS TO BE WOVEn/sEWN INTO ITS FABRic. Some parts can be vital or inseparable even when they are not seen as positive and beneficial parts of the national fabric (e.g. racism, slavery, guns). Some examples highlight the difficulty of removing this vital part without grave consequences while others bring into focus the violence necessary to remove it (example 28). The verb weave into is especially prominent in such examples in the corpus. Other verbs from the domain FABRIC include interweave and sew into.

(23) And yes, expect to hear "Eye of the Tiger" on Saturday. "The song is still in the fabric of America," said Peterik, 55.

(24) He [= Nelson Mandela]'s sewn into the fabric of what South Africa is.

(25) The nuclear taboo in Japan since Hiroshima is still a strong part of the national fabric.

(26) Love them or hate them, guns - and the arguments about them - are woven into the very fabric of our society.

(27) And also racism is an integral - woven into the fabric of this country.

(28) After Islam was ripped out of Turkey's social fabric by the reforms of Mustafa Kemal in the 1920s [...]

As we saw, the national fabric is not immutable. According to examples from the corpus, new entities can become part of the national fabric. This process is usually gradual and lengthy (example 29), it may require conscious effort, as suggested by the verb weave oneself into in example 30 , or may be done gradually and surreptitiously, as suggested by the use of insinuate oneself into in example 31 and expressions such as subtle infiltration and creep into elsewhere in the corpus. 
(29) "It might take decades," he added, "before democracy and the respect for minority rights are a part of the fabric of Kosovo."

(30) $[\ldots]$ they [=civic activists]'re determined not to blow this golden opportunity to weave themselves into China's social fabric.

(31) Shopping also has seamlessly insinuated itself into the fabric of the country.

Throughout the corpus, the most prominent parts of nations are individuals and groups. Some examples portray members of nations not simply as passive parts of a nation, but as its active and productive members - they are conceptualized as participating and contributing to the national fabric and these contributions themselves can become part of the nation in question. This is a recurring idea in the corpus, which emphasizes the importance of members being a force for good in their nations e.g. by being law-abiding citizens, paying taxes, being active members of their communities and the society at large, etc. Sections 3.5 and 3.6 will return to this idea with regard to minority groups, marginalized individuals and groups and immigrants.

(32) The contributions of many individuals are recorded in the fabric of our society.

(33) The society benefits in many ways from having stable, intact families. They pay taxes, raise children and are the fabric of a healthy society. It is an American value.

(34) It's a chance for us to give veterans who have really sacrificed an arm, or a leg, or more for our country to be able to let them have a chance to participate in the fabric of our country and continue to contribute.

\subsection{Marginalized and stigmatized individuals and groups}

Even though living in a particular geographic space (a country or territory) is a crucial element of the definition of a nation, examples from the corpus indicate that certain individuals and especially groups that meet this criterion are not necessarily considered to be parts of the national fabric. These are usually minority groups (religious, ethnic, racial, sexual, etc.) and economically disadvantaged people. The use of metaphor and metaphorical scenarios to stigmatize and marginalize individuals and groups has been explored in literature. For example, Musolff (2016) discusses the use of the PARASITE scenario to portray groups such as Jews in post-First World War Germany as a social threat. Santa Ana (2002) studies the negative representations of Latinos in American public discourse, showing how metaphors are used to depict them as A DISEASE, OUTSIDERS and DANGEROUS WATERS inflicting harm on the American nation. Analyzing data from several corpora, Potts and Semino (2019) identify CANCER as a source domain used to represent people's negative impact on a place (including nations) - "PEOPLE (singular, 
plural, or universal) possessing out-group attributes or engaging in deviant behaviors are constructed as a "cancer" of their environs" (Potts and Semino 2019: 90). As argued by Goatly (2007: 86), the RACE IS COLOR metaphor "helped in the stereotyping and discrimination that dogged the $19^{\text {th }}$ and most of the $20^{\text {th }}$ century and was complicit with imperialism and the construction of the other as inferior". An important aspect in the use of metaphors to talk about individuals and groups is that they can be employed to construct in-group ("us") and out-group ("them/others") identities. This mechanism reflects but also shapes perceptions of who belongs in a group and who does not, which can result in discrimination and inequality (see e.g. Knoblock 2017; Tripler and Ruscher 2014) and legitimize discrimination and inequality through a form of manipulation that consists of positive self-presentation and negative other-presentation (van Dijk 2006).

In a similar way, the metaphors NATIONS ARE FABRICS and TO BE AN (INSEPARABLE/ VITAL/UBIQUiTOUS) PART OF A NATION IS TO BE WOVEN/SEWN INTO ITS FABRIC can be used to bring into question the status of certain individuals and especially groups in their nations (example 35) or to draw attention to their marginalization and exclusion from the national fabric and the negative impact that this might have (examples 36 to 39).

(35) So how do Hispanics fit into the fabric of the United States?

(36) There are people who are Indian-American who are kind of concerned about whether or not this will in fact be another opportunity to kind of mock the browns. [...] a group that already has often been, you know, misperceived as being foreigner or not kind of part of the American fabric.

(37) The effects of marriage as an institution coupled with post-9/11 politics further produces liminal and racialized bodies that are increasingly 'other' in that they are non-white, of the poor and working classes, and definitely not part of the national fabric of the US.

(38) $[\ldots]$ the dilemma facing many African countries has been how to incorporate previously privileged minority groups into the national fabric.

(39) They might do some damage, but I would say less damage than tearing up the national fabric by essentially saying to a member, a citizen of our country, we're cutting you off.

These metaphors are also used in contexts where there is a need to (re)assert someone's place in the national fabric. In many cases, members of marginalized and minority groups themselves feel the need to speak on behalf of their entire group in order to assert their place in their nation (indicated by the use of we, us, our, ours).

(40) They are engaged in multifaceted efforts to revitalize their cultures, assert the legitimacy of their culturally-based values and practices as integral to the fabric of Canadian society as a whole $[\ldots]$ 
(41) Walking while brown, you're stopped because of your accent, the color of your skin. And that's wrong. We're all part of the American fabric.

(42) We're treated and talked about today as if Muslims are not Americans. We are Americans. We are doctors, we are investment bankers, we are taxi drivers, we are storekeepers, we are lawyers. We are part of the fabric of America.

In the conceptualization of how the marginalized individuals and groups described above fit into the national fabric of their countries, the matter of their contribution to the nation and society in question often arises. For instance, in example 43, a disadvantaged group, the homeless, are contrasted with contributing members of society - 'people like you and me who hold down jobs and seem to be regular parts of fabric of society'. Similarly, Mormons in example 45 seem to have become fully integrated into their nation solely because of their contribution and adherence to positive values and socially acceptable behavior.

(43) This whole sort of - the idea of this homelessness, and the distance between, I think, people like you and me who hold down jobs and seem to be regular parts of fabric of society, and folks who may be pushing a shopping cart around in Central Park two blocks from here, it really isn't that great.

(44) $[. .$.$] how Mexican-Americans and all people have contributed to the fabric$ of this great nation.

(45) But thanks to their industry, optimism and civic-mindedness, many Mormons have found their place in the American fabric.

\subsection{Immigration}

Metaphors related to immigrants and immigration in contemporary English have been studied extensively, especially in discourse (see e.g. Charteris-Black 2006; Cisneros 2008; Cunningham-Parmeter 2011; Dervinytè 2009; Goatly 2007; Knoblock 2017; Musolff 2015, 2016; Santa Ana 2002). Most metaphors identified in these studies paint a dehumanizing picture of immigrants as dangerous, inferior, out-group and "other". For example, Santa Ana (2002) shows how the Latino population in the US is (mis)represented as immigrants in public opinion by exploring metaphors in newspaper discourse. He discovers that NATION is conceptualized as A HOUSE being attacked by immigration, as a sinking sHIP being overloaded by the influx of immigrants, and as A BODY burdened by immigration. At the same time, immigrants are represented as DANGERous WATERS/FLOODWATERS, ANIMALS, DISEASE AND WEEDS. Musolff $(2015,2016)$ studied the metaphor scenarios in British online and newspaper debates on immigration. His findings include metaphorical constructions of THE NATION-STATE 
as a CONTAINER and IMMIGRANTS as OUTSIDERS, a FLOOD/TIDE/WAVE WANTING TO ENTER THE CONTAINER, IMMIGRANTS as SCROUNGERS (especially PARASITES) and a harmful influence on British culture (Musolff 2015, 2016). Knoblock (2017) explores the negative views about Muslims in social media posts and finds metaphors portraying MusLims as ANIMALS, ISLAM as a DISEASE and MuSLIM IMMIGRANTS as a FLOOD or CARGO, creating an overall picture that they are dangerous as well as undesirable in the American society.

The conceptualization of NATIONS as FABRIC offers two opposite perspectives on immigration and immigrants and, occasionally, migrants and refugees. First, (illegal) immigration/migration is seen as having a negative impact on the country in question it is said to be straining, fraying, weakening or ripping at the national fabric. Here, too, the notion of immigrants as "others" and "them" is sometimes invoked (example 49).

(46) [...] our nation's social fabric does appear to be fraying from such strains as illegal immigration and the culture wars.

(47) The toleration of illegal immigration undermines all of our labor; it rips at the social fabric. It's a race to the bottom.

(48) [...] Viktor Orban, doesn't seem to share that same belief, warning repeatedly that his nation must defend its Christian traditions against this coming wave of Muslims, the implication being, refugees will inevitably change the fabric of Hungary for the worse.

(49) Like the Nativists of the 1920s, the Individualists of 2010 view the present as a period when forces from the outside (read immigrants) threaten the very fabric of their monochromatic fantasy Americana quilt.

On the other hand, the same metaphor can be used to frame IMMIGRATION as a positive force strengthening the national fabric. At the same time, however, positive views on immigrants and their place in the nation in question are occasionally supported by arguments referring to their positive contribution to their nation or society. Musolff (2015: 46) identifies a similar attitude to immigrants in British online and newspaper discourse, which he identifies as the GAIN sub-scenario regarding the effect of immigrants in the UK. As the only positive scenario identified by Musolff, it is used to defend the immigration of some groups, such as academics and skilled workers, to the UK because they may benefit its economy. As we saw earlier, individuals and groups who are viewed as participating and contributing to the national fabric are seen as legitimate parts of their nation. The same idea is often echoed when discussing immigrants, whose positive image is sometimes conditional on whether they contribute to their countries, adhere to certain beliefs and engage in certain kinds of behavior. For example, they are regarded positively if they add value to the fabric of the country (example 51), if they become law-abiding citizens (example 52) or they are perceived 
as critical parts of the national fabric because they are god-fearing and hardworking (example 53).

(50) Fote counters that immigrants strengthen the U.S. economy, diversify the social fabric of society [...]

(51) In light of events this weekend, I want to reiterate my support for coworkers, founders, entrepreneurs and students who are immigrants. You have, and will continue to add value to the fabric of our country and we, as Americans, should always welcome you with open arms, minds and hearts.

(52) Very few Americans are opposed to immigrants entering and becoming part of our fabric if they follow the lawful rules and regulations which are very clearly defined and have long been in place.

(53) [...] I've had a very reasonable position on immigration. I have always said Hispanics are such a critical part of the fabric of the United States. They occupy jobs from top to bottom. They're so critical to our country, they're god fearing and they're hardworking.

Finally, immigrants who have been fully integrated into their country are considered to be parts of the national fabric. The relevant conceptual metaphors are TO ASSIMILATE/INTEGRATE AN INDIVIDUAL/GROUP INTO A NATION IS TO INCORPORATE THEM INTO THE NATIONAL FABRIC and TO BECOME ASSIMILATED/FULLY INTEGRATED INTO A NATION IS TO BECOME A PART OF ITS FABRIC. Once again, some examples from the corpus suggest that this integration depends on the kind of activities, behavior, beliefs and values that characterize the immigrants - e.g. whether they are contributing and whether they are characterized as hard-working and prosperous.

(54) "Americanization" was a term used to describe early efforts in this country to quickly assimilate the newly arriving waves of immigrants into the fabric of American life.

(55) It's how we can work with those communities in the United States to enhance their integration into the fabric of American society [...]

(56) But as these Irish immigrants sank roots in American society, their descendants prospered and became part of the essential fabric of American life.

\section{Discussion and conclusion}

The analysis of the NATIONS ARE FABRICS metaphor in the COCA corpus has shown that it can be employed to refer to various aspects of nations and that it is common in all genres except fiction. The most frequent metaphorical linguistic expressions in the 
corpus, apart from the noun fabric, are all verbs describing how nations change (e.g. reweave), the damage inflicted on them (e.g. rip apart, slash at) and the integration of nations' constituent parts into their fabrics (e.g. weave into). Other expressions with multiple occurrences in the corpus include participles and adjectives describing the qualities of the national fabric (e.g. frayed, delicate). Linguistic expressions referring to other features of fabrics, e.g. their specific parts (seams, strands, threads, fibers, patches) or the type of fabric (e.g. quilt) were all rare or one-off occurrences in the corpus. While these findings are sufficient to lend themselves to the claim that FABRIC is a common source domain for NATIONS, further research could be conducted to explore whether other metaphorical expressions from this domain (both those that occur in the corpus alongside fabric and those that do not) reveal additional aspects of nations not identified here. Future research could also examine what mappings occur between other SOCIAL ENTITIES (from regions and continents to cities, communities and neighborhoods) and FABRICS.

Metaphorical mappings are partial in nature and for each source domain "only certain aspects of it are conceptually utilized and activated in the comprehension of a target domain" (Kövecses 2010: 94). In this way, source domains highlight certain parts of the target domain, but also necessarily hide others (Lakoff and Johnson 1980: 10-13; Kövecses 2010: 91-103). The features of FABRICs that were found to map onto NATIONS as social entities are their complexity, the multitude and interconnectedness of their constituent parts, the changes that can occur in their structure and the damage they can sustain. All of this supports Grady's analysis of the complex metaphor SOCIETY IS A FABRIC into two primary metaphors. Grady (1997b: 285) argues that the metaphor MULTIPLE INTERDEPENDENCE IS INTERWEAVING helps explain why interconnectedness and multiple interdependence are the only features of fabric that map onto abstract entities whereas "[s]alient features and functions of fabrics do not enter into the mapping e.g., color, weight, material, use". None of these features map onto NATIONS in our corpus. As COMPLEX PHYSICAL STRUCTURES, FABRICS map onto NATIONS to enable us to conceptualize their complexity and heterogeneity, but also their UNIQUE IDENTITY and BASIC STRUCTURE, made up of many interconnected parts. A nation's complex structure is held together by the relations among its members. Depending on the type of these relations, they can maintain and strengthen the national fabric or they can be forces that undermine, damage or destroy it. NATIONS as bodies of people are thus conceptualized as FABRIC in order to focus on the key political, social, economic and cultural practices, values and issues that are considered to define the identity of nations, bring about changes in them and present threats to their existence and identity. These findings add to the body of work on the metaphorical representation of nations by providing an in-depth exploration of a metaphor that has previously not been studied in any detail. 
The metaphor NATION as FABRIC and other related metaphors also bring the constituent parts of nations into focus. These are almost inevitably essential and integral parts that define their identity. At the same time, this metaphor is used to distinguish between individuals and groups who are considered to be fully integrated members of their nations, those who are not and those whose status is being questioned. It therefore reveals perceptions of how various individuals and especially minority groups, marginalized groups and immigrants fit (or do not fit) into the society at large. A recurring idea in the corpus is that only those individuals and groups contributing to their nations, for example economically, are likely to be perceived as their rightful and fully-integrated members. These findings provide an additional perspective on the metaphorical representation of marginalized individuals and groups such as immigrants, religious minorities and racial minorities since metaphors identified in previous research mostly concern negative perceptions of these individuals and groups. The NATIONS as FABRIC metaphor, however, enables us to conceptualize their in-group and out-group status and the process of their integration into the nation or society in question. The analysis reveals that in-group status can be denied to members of nations even when they meet the formal criteria for belonging to a nation, such as legally living and working within their geographical space. It also indicates that, while it is possible for them to become rightful parts of their nations, the change from an out-group to in-group status for these individuals and groups is often conditional on whether they meet certain criteria or expectations.

The mappings identified between NATIONS and FABRIC, especially those that reveal what members of nations are perceived as fully integrated into the national fabric and why, could have implications for research into these conceptual metaphors in discourse, given that metaphor can construct and shape public discourse and be a vehicle of manipulation and persuasion (see e.g. Charteris-Black 2004, 2005; Goatly 2007; Lakoff 2003) and that the choice among various alternative source domains in discourse is usually not neutral but is instead influenced by a range of social, political, historical and other factors and motivations (Semino 2008). Future studies could, therefore, look into how the NATIONS as FABRIC metaphor is employed in discourse, especially to determine if it is used to form or perpetuate negative opinions of certain groups by shaping the public and political discourse on them. 


\section{References}

Breban T. and K. Davidse (2016). The History of Very: The Directionality of Functional Shift and (Inter)subjectification. English Language and Linguistics, 20(2), 221249.

Charteris-Black, J. (2004). Corpus Approaches to Critical Metaphor Analysis. Basingstoke: Palgrave.

Charteris-Black, J. (2005). Politicians and Rhetoric: The Persuasive Power of Metaphor. Basingstoke: Palgrave.

Charteris-Black, J. (2006). Britain as a Container: Immigration Metaphors in the 2005 Election Campaign. Discourse \& Society, 17(5), 563-581.

Cisneros, J. D. (2008). Contaminated Communities: The Metaphor of 'Immigrant as Pollutant' in Media Representations of Immigration. Rhetoric \& Public Affairs, 11(4), 569-601.

Cunningham-Parmeter, K. (2011). Alien Language: Immigration Metaphors and the Jurisprudence of Otherness. Fordham Law Review, 79(4), 1544-1598.

Davies, M. (2010). The Corpus of Contemporary American English as the First Reliable Monitor Corpus of English. Literary and Linguistic Computing, 25(4), 447-464.

Dervinyte, I. (2009). Conceptual Emigration and Immigration Metaphors in the Language of the Press: A Contrastive Analysis. Studies about Languages, 14, 49-55.

Gibbs, R. W. Jr. (2006). Cognitive Linguistics and Metaphor Research: Past Successes, Skeptical Questions, Future Challenges. D.E.L.T.A., 22(Especial), 1-20.

Gibbs, R. W. Jr. (ed.) (2008). The Cambridge Handbook of Metaphor and Thought. New York: Cambridge University Press.

Gibbs, R. W, Jr. and T. Matlock (2008). Metaphor, Imagination, and Simulation: Psycholinguistic Evidence. In: R. W. Gibbs, Jr. (ed.), The Cambridge Handbook of Metaphor and Thought, New York: Cambridge University Press, 161-176.

Goatly, A. (2007). Washing the Brain: Metaphor and Hidden Ideology. Amsterdam/ Philadelphia: John Benjamins Publishing Company.

Grady, J. E. (1997a). Foundations of meaning: Primary metaphors and primary scenes. Unpublished $\mathrm{PhD}$ dissertation. University of California, Berkeley.

Grady, J. E. (1997b). THEORIES ARE BUILDINGS Revisited. Cognitive Linguistics, 8(4), 267-290.

Klikovac, D. (2008). Metafore u mišljenju i jeziku. Beograd: XX vek.

Knoblock, N. (2019). Xenophobic Trumpeters: A Corpus-assisted Discourse Study of Donald Trump's Facebook Conversations. In A. Musolff (ed.), Language 
Aggression in Public Debates on Immigration, Amsterdam/Philadelphia: John Benjamins, 123-149.

Kövecses, Z. (2009). Metaphor and Poetic Creativity: A Cognitive Linguistic Account. Acta Universitatis Sapientiae, Philologica, 1(2), 181-196.

Kövecses, Z. (2010). Metaphor: A Practical Introduction. $2^{\text {nd }}$ edition. Oxford: Oxford University Press.

Lakoff, G. (1996). Moral Politics: What Conservatives Know That Liberals Don't. Chicago/London: University of Chicago Press.

Lakoff, G. (2003). Metaphor and War, Again. UC Berkeley. (10 September 2019) $<$ https://escholarship.org/uc/item/32b962zb>.

Lakoff, G. (2004). Don't Think of an Elephant! Know your Values and Frame the Debate. White River Junction, Vermont: Chelsea Green Publishing.

Lakoff, G. and M. Johnson. (1980). Metaphors We Live By. Chicago: University of Chicago Press.

Lakoff, G. and M. Johnson. (1999). Philosophy in the Flesh: The Embodied Mind and Its Challenge to Western Thought. New York: Basic Books.

Musolff, A. (2006). Metaphor Scenarios in Public Discourse. Metaphor and Symbol, 21(1), 23-38.

Musolff, A. (2012). Special Feature: The Study of Metaphor as Part of Critical Discourse Analysis. Critical Discourse Studies, 9(3), 301-310.

Musolff, A. (2015). Dehumanizing Metaphors in UK Immigrant Debates in Press and Online Media. Journal of Language Aggression and Conflict, 3(1), 41-56.

Musolff, A. (2016). Political Metaphor Analysis: Discourse and Scenarios. London: Bloomsbury.

Potts, A. and E. Semino (2019). Cancer as a Metaphor. Metaphor and Symbol, 34(2), $81-95$.

Pragglejaz Group. (2007). MIP: A Method for Identifying Metaphorically Used Words in Discourse. Metaphor and Symbol, 22(1), 1-39.

Quirk, R. et al. (1985). A Comprehensive Grammar of the English Language. London: Longman.

Rasulić, K. (2003). Konceptualizacija društva pomoću vertikalne dimenzije. In: D. Klikovac, and K. Rasulić (eds.), Jezik, društvo i saznanje. Beograd: Filološki fakultet, 239-254.

Rasulić, K. (2004). Jezik i prostorno iskustvo: Konceptualizacija vertikalne dimenzije u engleskom i srpskohrvatskom jeziku. Beograd: Filološki fakultet.

Santa Ana, O. (2002). Brown Tide Rising: Metaphors of Latinos in Contemporary American Public Discourse. Austin: University of Texas Press. 
Semino, E. (2008). Metaphor in Discourse. Cambridge: Cambridge University Press. Steen G. J. (2011). The Contemporary Theory of Metaphor - Now New and Improved! Review of Cognitive Linguistics, 9(1): 26-64.

Steen, G. J. et al. (2010). A Method for Linguistic Metaphor Identification: From MIP to MIPVU. Amsterdam/Philadelphia: John Benjamins.

Tipler, C. and J. B. Ruscher (2014). Agency's Role in Dehumanization: Non-human

Metaphors of Out-groups. Social and Personality Psychology Compass, 8(5): 214 228.

van Dijk, T. A. (2006). Discourse and Manipulation. Discourse \& Society, 17(3), 359383.

\section{Sources}

Contemporary Corpus of American English (COCA). (8 November 2018) $<$ https://www.english-corpora.org/coca/>.

MacMillan Dictionary. (10 November 2018) $<$ https://www.macmillandictionary.com/>.

Merriam-Webster Unabridged. (10 November 2018) $<\mathrm{http}$ ://unabridged.merriam-webster.com/>.

Oxford Dictionaries' English Dictionary (now Lexico). (10 November 2018) $<$ https://www.lexico.com/en>. 